\title{
La categoría de género y las distintas formas de injusticia. Una invitación a repensar los "quiénes" de la justicia*
}

\author{
The Gender Category and the Various Forms of Injustice. An Invitation \\ to Rethink about the "Who" of Justice \\ A categoria de gênero e as diferentes formas de injustiça. Um convite \\ a repensar os "quem" da justiça
}

\section{MARILUZ NOVA LAVERDE}

FECHA DE RECEPCIÓN: 30 DE ENERO DE 2016. FECHA DE ACEPTACIÓN: 2 DE MARZO DE 2016

DOI: DX.DOI.ORG/10.12804/ESJ 18.02.2016.03

Para citar este artículo: Nova, M. (2016). La categoría de género y las distintas formas de injusticia. Una invitación a repensar los "quiénes" de la justicia. Estudios Socio-Jurídicos, 18(2), 89-116. Doi: dx.doi.org/10.12804/ esj 18.02.2016.03

\section{RESUMEN}

Tras una revisión de los debates de Filosofía Política contemporánea sobre justicia social, se observa que la teoría crítica hoy tiene el gran reto de abordar, en un mismo marco interpretativo, las formas de injusticia. En consecuencia, se propone reestructurar las cuatro grandes problemáticas identificadas en dos irreductibles dimensiones de la justicia: redistribución y reconocimiento. Con base en una reconceptualización de los "quiénes" de la justicia, la segunda dimensión -el reconocimiento-, además de los asuntos de género, comprende el trato a personas con diversas capacidades físicas y mentales, así como los conflictos transnacionales. Este marco interpretativo ilustra los alcances y las limitaciones de la categoría de género como instrumento de análisis de injusticias, violencias, opresiones y discriminación presentes en la sociedad actual.

Palabras clave: justicia, reconocimiento, género, redistribución.

* Este artículo forma parte de los resultados del proyecto de investigación "Democracia y capitalismo tardío, el caso colombiano. Consideraciones en el marco de la búsqueda de salidas negociadas al conflicto armado". Se sustenta en el tercer capítulo de la tesis doctoral de la autora, Hacia una utopía realista: redistribución y reconocimiento. Una concepción política de justicia como fundamento de una aproximación a un índice de justicia social (Nova, 2015).

** Doctora en Estudios Políticos y Relaciones Internacionales, de la Universidad Nacional de Colombia. Docente investigadora de la Universidad de La Salle. Correo electrónico: mariluznoval@ gmail.com 


\section{ABSTRACT}

Through a review of contemporary political philosophy debates on social justice, this paper shows that critical theory today has the big challenge of addressing the various forms of injustice in the same interpretative framework. Consequently, it is proposed to restructure the four major issues identified in two irreducible dimensions of justice: redistribution and recognition. Based on a re-conceptualization of the "who" of justice, the second dimension, the recognition, besides gender issues comprises the treatment of people with different physical and mental abilities, as well as transnational conflicts. This interpretative framework illustrates the scope and limitations of the category of gender as an analytical tool of injustice, violence, oppression and discrimination present in society today.

Keywords: justice, recognition, gender, redistribution.

\section{RESUMO}

Depois de uma revisão dos debates de Filosofia Política contemporânea sobre justiça social, se observa que a teoria crítica hoje tem o grande reto de abordar, em um mesmo marco interpretativo, as formas de injustiça. Em consequência, se propõe reestruturar as quatro grandes problemáticas identificadas em dois irredutiveis dimensões da justiça: redistribuição e reconhecimento. Com base em uma reconceitualização dos "quem" da justiça, a segunda dimensão -o reconhecimento-, além dos assuntos de gênero, compreende o trato a pessoas com diversas capacidades físicas e mentais, assim como os conflitos transnacionais. Este marco interpretativo ilustra os alcances e as limitações da categoria de gênero como instrumento de análise de injustiças, violências, opressões e discriminação presentes na sociedade atual.

Palavras-chave: justiça, reconhecimento, gênero, redistribuição. 


\section{Introducción}

El objetivo del artículo es examinar los alcances y las limitaciones de la categoría de género como instrumento de análisis de injusticias, violencias, opresiones y discriminación presentes en la sociedad actual. En la primera sección se reseñan las recientes disertaciones teóricas elaboradas alrededor de la noción de justicia social y se identifican cuatro principales tópicos de interés. En la segunda parte se propone un marco interpretativo integrador de las problemáticas enunciadas mediante la reconceptualización de los quiénes de la justicia, con el fin de ubicar las cuestiones de género como una de las luchas por el reconocimiento. Por último, se enuncian algunas conclusiones.

\section{Debates posrawlsianos sobre la justicia}

En el campo del conocimiento revivido por Rawls y que Iris Marion Young (1998) describe como aquel de la "politización de lo social", la cuestión de la justicia social es central. Teoría de la justicia, la obra seminal de Rawls (2011), publicada en 1971, constituye el resurgimiento del tema de la justicia como objeto de estudio de la teoría política, al punto que, como lo reconoce Nozick (1974), en la actualidad, los filósofos de la política deben trabajar dentro de la teoría de Rawls o explicar por qué no lo hacen. D'Agostini (2000) muestra a Rawls como el precursor del reciente giro ético de la Filosofía, el cual se consolida con los replanteamientos de Rawls veinte años después en el Liberalismo político (2006).

Con su obra, Rawls reivindicó y posicionó la justicia social en la teoría política contemporánea. En los trabajos posteriores podemos identificar cuatro corrientes representativas: la primera, la reacción comunitarista encabezada por Michael Sandel, Michael Walzer, Alasdair MacIntyre y Charles Taylor, que controvierte el proyecto liberal de la Modernidad. La segunda, desde un marxismo heterodoxo, comprende a su vez dos vertientes: los debates de las feministas estadounidenses en los trabajos de Iris Marion Young, Seyla Benhabib y Nancy Fraser, a los que se suma, desde la tercera generación de la Escuela de Frankfurt, Axel Honneth, cuyo debate con Fraser plantea un dilema (¿falso?) entre redistribución y reconocimiento y, con él, James Boh- 
man y Chantal Mouffe, quienes convergen en una propuesta de democracia radical. La tercera, el marxismo analítico, con Gerard Cohen y Philippe van Parijs, entre otros, invita a releer ideas marxistas como la autorrealización y la explotación y a analizar la propuesta de un ingreso básico incondicional como "vía capitalista al comunismo". La cuarta, desde el enfoque de las capacidades, encontramos a Martha Nussbaum y Amartya Sen; la primera precisa una lista de mínimos de dignidad e identifica como problemas no resueltos de la justicia el trato a las personas con discapacidades, el alcance de la justicia más allá del Estado-Nación y los deberes hacia los animales no humanos y Amartya Sen (2010) hace un llamado por la factibilidad de los criterios de justicia y se opone a lo que él denomina el "institucionalismo trascendental" imperante en las modernas teorías de la justicia.

Las perspectivas enunciadas son presentadas a continuación, entrecruzadas en cuatro temáticas definidas: distribución, reconocimiento, trato a discapacitados y justicia transnacional. Se hace la salvedad de que la forma expositiva elegida para presentar los debates no pretende seguir una clasificación por líneas de pensamiento, ${ }^{1}$ sino mediante la identificación de las cuestiones nucleares de una teoría de la justicia hoy, las cuales permiten ilustrar los alcances y las limitaciones del concepto de género en el espectro amplio de injusticias, violencias, opresiones y discriminación. En sintonía con esta clasificación, el Social Justice Research, revista oficial de la International Society for Justice Research (ISJR), presentó un balance de cerca de veinticinco años de publicaciones, desarrollado por Törnblom Kjell y Kazemi Ali (2011) señalan una línea de investigación predominante: la que explora las relaciones entre las emociones y la equidad con base en la psicología. Identifican también áreas de interés que progresivamente concentran atención: el reconocimiento de individuos, colectividades y animales no humanos excluidos de la comunidad moral, así como los asuntos de justicia distributiva. Por último, muestran la necesidad de articular dicho tópico. En él se identifican las áreas de mayor investigación, así como los principales desafíos. Sobre las primeras, señalan una línea de investigación predominante en la que se exploran las relaciones entre las emociones y la equidad con base en la psicología. Además, se identifican áreas de interés que concentran atención en el reconocimiento de individuos, colectividades y animales no 
humanos, excluidos de la comunidad moral; así como asuntos de justicia distributiva. Por último, muestran la necesidad de articular dichos tópicos.

\subsection{La problemática de la mala distribución}

Las réplicas a la concepción rawlsiana de justicia distributiva comprenden diferencias respecto a qué, cómo y entre quiénes se distribuye; esto es, respectivamente, críticas a la teoría de los bienes primarios, al principio de la diferencia y al orden lexicográfico que lo relaciona con el primer principio y los postulados del modelo contractualista.

Desde la corriente comunitarista, Walzer (1983) y MacIntyre (1981) sostienen que la prefiguración de unos bienes primarios resulta de una lectura hegemónica de las necesidades que, como tal, niega las diferencias $y$, en consecuencia, insisten en que la definición de los mismos debe ser objeto de un consenso fundamental.

Gerard Cohen (2001) ataca el principio de diferencia y el criterio asociado del maximin que supone, que una transferencia que acreciente la desigualdad es justa, siempre y cuando mejore la condición de los menos aventajados, lo cual fundamenta un conformismo con el liberalismo y la desigualdad.

Por su parte, Van Parijs (1996) cuestiona el orden lexicográfico de los dos principios, al considerar que, ante profundas desigualdades, los individuos estarían dispuestos a renunciar a algún grado de libertad a cambio de mayor igualdad de oportunidades. Van Parijs pretende suministrar una respuesta creîble a la amenaza liberal según la cual considerar en serio la libertad exige admitir o aceptar la mayor parte de las desigualdades del mundo actual. Su reflexión inicia con el estudio de la teoría de la explotación de John Roemer, quien lo impulsó en su análisis crítico de las condenas éticas al capitalismo. ${ }^{2}$ Su objetivo ha sido develar en qué consiste lo que está mal en las sociedades capitalistas y, tras este propósito, abordó las teorías liberales de la justicia. Elaboró su propuesta de un ingreso básico incondicional ${ }^{3}$

2 Libertad real para todos es un intento de representar y organizar la intrincada red de argumentos y contraargumentos sobre la legitimidad del capitalismo que han venido desarrollándose en las últimas dos décadas, como resultado de la mutua fecundación producida entre la teoría económica y la Filosofía Política (Van Parijs, 1996).

3 Raventós (2007) elabora una justificación no liberal, republicana, de una renta básica soportada en el derecho a la existencia y las condiciones materiales de la libertad. 
soportada en una concepción de justicia social, en tanto distribución justa de la libertad real para perseguir la ejecución de nuestra concepción de la vida buena, cualquiera que esta sea (Van Parijs, 2008). La libertad real, a diferencia de la formal, no solo tiene que ver con el derecho de hacer lo que uno puede querer hacer, sino también, si cuenta con los medios para hacerlo. Libertad real, dice Van Parijs, es "libertad negativa", si la confrontamos con la participación política llamada "libertad de los antiguos". También lo es en el sentido de que es libertad de hacer "cualquier cosa que uno pueda querer hacer", más que la libertad de hacer lo que viene dictado por los deberes morales o por preferencias autónomamente elegidas. En este marco, un ingreso básico incondicional es entendido como una propuesta posrawlsiana desde el marxismo analítico que se autoproclama como una "vía capitalista al comunismo" (Van Parijs y Van der Veen, 1988, pp. 19-46).

Habermas (Habermas y Rawls, 1998), Nussbaum (2007) y Sen (1998) coinciden en cuestionar la centralidad de los bienes en las consideraciones distributivas. Habermas reclama que el objetivo de una justa distribución ha de ser la autonomía de los sujetos mediante el ejercicio de sus derechos, mientras Sen evoca el desarrollo de las capacidades de los agentes. Como lo mencionamos en el apartado anterior, Sen identifica como debilidad de la propuesta rawlsiana el que se asuman los bienes primarios como la materialización de la justicia de una situación, en cambio de considerarse la relación entre personas y bienes como aquella de la que se derivan beneficios (Sen, 1998). En otras palabras, lo que Sen sostiene es que la igualdad de bienes no implica igualdad de capacidades, porque la relación entre personas diversas y bienes conlleva diferentes realizaciones de capacidades. ${ }^{4}$ En el mismo sentido, Nussbaum se aparta de la teoría de los bienes primarios propuestos por Rawls y sostiene que el mejor modo de plantear la idea de un mínimo social básico es un enfoque basado en las capacidades humanas.

Respecto a entre quiénes se distribuye, Nussbaum $(2007)^{5}$ hace una crítica al criterio fundamental del beneficio mutuo de la teoría clásica del

4 Recordemos que Rawls responde a estas críticas de Sen al afirmar que los bienes sociales primarios sí toman en cuenta las capacidades de los ciudadanos como personas libres e iguales en virtud de sus dos facultades morales y que es mediante la relación entre los bienes primarios y los ciudadanos como se ejercen esas facultades, lo que les permite ser miembros normales y plenamente cooperativos (Rawls, 2002).

5 Libro escrito en memoria de Rawls. 
contrato social, ${ }^{6}$ el cual permea los planteamientos de Rawls. Este criterio propicia que al menos tres problemas de la justicia no queden resueltos. Sobre los problemas sin solución volveremos más adelante; por ahora, retomamos la crítica metodológica. Nussbaum se propone analizar las limitaciones de la tradición del contrato social, la cual, en la medida en que promueve una visión de la sociedad como un contrato entre personas libres, iguales e independientes fundamentado en el beneficio mutuo ${ }^{7}$ que, por lo general, no distingue entre quienes diseñan los acuerdos y quienes son los receptores o sujetos de los mismos, ${ }^{8}$ promueve exclusiones graves en términos de justicia con las personas con deficiencias físicas o mentales o los animales no humanos, por ejemplo. En otras palabras, reproduce asimetrías de poder o profundiza desigualdades. Esta crítica sobre los quiénes sujetos de la justicia en realidad trasciende la cuestión distributiva y constituye la siguiente temática gruesa de los debates posrawlsianos sobre justicia social: el reconocimiento.

\subsection{La problemática de la falta de reconocimiento}

Han sido los debates de las feministas estadounidenses los que han nutrido con más contundencia la reivindicación del reconocimiento como

6 Nussbaum (2007) distingue tres formas contemporáneas de contractualismo: la primera es una forma egoísta, en la que los principios políticos con contenido moral se fundan en exclusiva en el beneficio mutuo, sin premisas morales (por ejemplo, la teoría de Gauthier). La teoría de Rawls es mixta, pues combina elementos del contrato social clásico con elementos de la moral kantiana que imponen limitaciones importantes sobre los principios políticos elegibles. Por último, hay contractualismos modernos de tipo kantiano, que parten de las ideas kantianas de equidad y mutua aceptabilidad sin remitirse a la idea de beneficio mutuo (por ejemplo, los trabajos de Thomas Scanlon en Ética y Brian Barry en Teoría Política). De los tres modelos considera superior el de Rawls, aunque insuficiente en el abordaje de los tres problemas de justicia que ella plantea.

7 La noción moral básica dentro de la tradición es el beneficio mutuo y la reciprocidad entre las personas que establecen el contrato (Nussbaum, 2007).

8 "[...] el por quién y para quién no tienen por qué ir ligados de este modo. Se podría proponer una teoría en la cual muchos seres vivos, tanto humanos como no humanos, sean sujetos primarios de la justicia aunque no tengan capacidad para participar en el procedimiento por el cual se escogen los principios políticos. Si partimos de la idea de que hay muchos tipos distintos de seres vivos dotados de dignidad y merecedores de respeto, existen poderosas razones para ensayar una teoría de este tipo y separar las dos cuestiones. Cualquiera que piense así reconocerá desde el principio que la capacidad para establecer un contrato, y la posesión de las capacidades que hacen posible el beneficio mutuo en la sociedad resultante, no son condiciones necesarias para ser un ciudadano dotado de dignidad y que merece ser tratado con respeto en un plano de igualdad con los demás" (Nussbaum, 2007, p. 37). 
esfera de la justicia. La crítica de Nussbaum (2007) a la teoría del contrato social señaló:

Los teóricos clásicos asumieron en todos los casos que los agentes contratantes eran hombres más o menos iguales en capacidad y aptos para desarrollar una actividad económica productiva. Por esta razón excluyeron la de la posición negociadora a las mujeres (consideradas no productivas), a los niños y a las personas mayores, aunque sus intereses podían quedar representados por las partes presentes [...]. Las doctrinas contemporáneas del contrato han rectificado en cierta medida estas omisiones [...] aunque la idea de que la familia es una esfera privada inmune a la ley y al contrato no ha recibido siempre la crítica frontal que merece (pp. 34-35).

Iris Marion Young (2000) cuestiona la centralidad de la problemática de la distribución en las teorías de la justicia, toda vez que distrae la atención que debe prestarse a los fenómenos de opresión y dominación propios de las estructuras sociales y las instituciones capitalistas. ${ }^{9}$ Young (2000) analiza al quién sujeto de la justicia, con el propósito de concebirlo como un ser afectivo y corporal y defender un ideal de reconocimiento recíproco que propicie el libre desarrollo del sentido del yo. Young coincide con Seyla Benhabib (2006a) ${ }^{10}$ y los comunitaristas como Sandel (2000) en la crítica al "yo generalizado", disociado de su propia identidad, que rige las teorías contemporáneas de la justicia. En términos de Benhabib: para pensar el punto de vista del otro (los otros), estos deben verse no solo como "otros generalizados", sino también como "otros concretos", al otro como individuo único, constituido por su propia historia, sus capacidades, necesidades

9 "[...] desplazar la discusión sobre la justicia [...] hacia un contexto más amplio que incluya también la acción, las decisiones sobre la acción y la provisión de los medios para desarrollar y ejercer las capacidades [...]. Los conceptos de dominación y opresión, antes que el concepto de distribución, deberían ser el punto de partida para una concepción de la justicia social" (Young, 2000, p. 47).

10 La publicación original de Benhabib de Situating the Self, en 1992, sitúa las reivindicaciones reclamadas por el feminismo, el comunitarismo y el posmodernismo contra el universalismo de la Ilustración en tres temas generales: 1) el escepticismo respecto a una razón legislativa capaz de articular las condiciones necesarias para un punto de vista moral, una posición original o una situación de habla ideal; 2) el cuestionamiento al ideal abstracto y desarraigado, distorsionado y nostálgico del ego masculino autónomo que privilegia la tradición universalista, y 3) la revelación de la incapacidad de esta razón universalista legislativa frente a la indeterminación y multiplicidad de contextos y situaciones vitales (Benhabib, 2006). 
y limitaciones. ${ }^{11}$ El objetivo de Benhabib es situar decisivamente la razón y el ser moral en contextos de género y de comunidad.

La figura hegeliana de la "lucha por el reconocimiento" viene cobrando vigencia. Benhabib (2006b) reconstruye la reflexión por el reconocimiento, desde sus raíces en Hegel, "La política del reconocimiento" de Charles Taylor y la teoría sobre derechos multiculturales de Will Kymlicka. Benhabib considera que "La política del reconocimiento" de Taylor tiene peligrosas ambigüedades, producto de una confusión entre ontología y propugnación. Benhabib comparte la propuesta de Taylor, retroalimentada por Axel Honneth y Jessica Benjamin, en relación con la importancia de las prácticas sociales de reconocimiento y el desarrollo de nuestros sentidos de autoconfianza, autoestima y autorrespeto. ${ }^{12}$

El debate entre Fraser y Honneth (2006) pone esto de presente e ilustra con claridad que el reconocimiento (así como la distribución) es una categoría clave dentro de las concepciones de justicia hoy. Desde una posición crítica de la sociedad capitalista, ambos rechazan la visión economicista que reduce el reconocimiento a un simple epifenómeno de la distribución; sin embargo, difieren en cuanto Honneth concibe el reconocimiento como la categoría moral fundamental y la distribución como derivada de aquella, mientras Fraser rechaza la idea de subsumir la distribución en el reconocimiento y, en contraste con el monismo normativo de Honneth, propone una perspectiva dualista de la justicia que considere ambas categorías como cofundamentales. Conforme a su convicción de que la teoría crítica tiene que conectar la crítica de las anomalías sociales con una explicación de los procesos que han contribuido a velarlas, Honneth (2009) demuestra que con el capitalismo ha llegado a prevalecer una forma de praxis que obliga a ser indiferente a los aspectos de valor de otros seres humanos; en lugar de relacionarse entre sí y reconocerse, los sujetos se perciben como objetos que hay que reconocer según los intereses propios.

11 "De acuerdo con el punto de vista del otro generalizado, cada individuo es una persona moral investida con los mismos derechos morales que nosotros mismos; esta persona moral es también un ser razonante y actuante, capaz de tener sentido de justicia, de formular una visión del bien y de ser activo en su búsqueda. El punto de vista concreto del otro, en cambio, nos exige ver a toda persona moral como un individuo único, con historia vital, disposición y capacidades determinadas, así como con necesidades y limitaciones" (Benhabib, 2006, p. 22).

12 "Adhiero totalmente a esta tesis de la constitución intersubjetiva del sí mismo por medio de prácticas morales dialógicas. Lo que me queda menos claro son sus corolarios en la política" (Benhabib, 2006b, p. 98). 
A lo largo de sus obras, Honneth presenta la lucha por el reconocimiento como el camino promisorio para alcanzar la autorrealización de los sujetos y la conformación de sociedades no excluyentes: la calidad de las relaciones sociales de reconocimiento debe ser el punto de referencia de una concepción de la justicia social. Con respecto a las sociedades modernas, procede a partir de la premisa de que la finalidad de la igualdad social es permitir la formación de la identidad personal de todos los miembros de la sociedad (Honneth, 2007). En estos términos, identifica en las sociedades capitalistas tres esferas de reconocimiento y unos principios normativos correspondientes: el amor (la idea central de las relaciones íntimas), el principio de igualdad jurídica de trato (la norma de las relaciones jurídicas) y la estima social (norma de la jerarquía social). El amor reivindica el reconocimiento afectivo, el amor de sí; el derecho, como parte de la constitución del sujeto de derecho, respalda el respeto de sí y un criterio de solidaridad pretende desplazar al del éxito, como reconocimiento del otro en los vínculos sociales y culturales, determinante de la estimación o consideración de sí.

En términos generales, el reconocimiento del otro implica una reconfiguración de la esfera pública y la reivindicación del conflicto como elemento constitutivo de lo político, ${ }^{13}$ dos dimensiones de un ideal democrático emancipatorio. Sobre la primera cuestión, la crítica de Fraser (1997) al modelo liberal de la esfera pública burguesa es representativa. ${ }^{14}$ Señala que

13 Los feministas proponen entender la construcción de lo público como un proceso continuo que se basa en las relaciones intersubjetivas. Se destacan las nociones de públicos y contrapúblicos de Nancy Fraser (1997) "El punto es que, a este respecto [la definición de lo público], no existen fronteras naturales dadas a priori. Lo que debe considerarse como un asunto de interés común será decidido, precisamente, a través de la confrontación discursiva. De lo anterior se sigue que ningún tópico debe ser excluido previamente a tal confrontación. Por el contrario, la publicidad democrática exige garantías positivas de oportunidad para que las minorías puedan convencer a otros de que aquello que en el pasado no era público, en el sentido de no ser de interés común, debería serlo ahora" (p. 123).

14 Desde la perspectiva francesa, véase también el trabajo de Rosanvallon (2006) sobre la contrademocracia. Propone nuevas pistas para pensar una revolución democrática mediante la consideración de que la experiencia democrática trasciende las esferas institucionales de elección y representación. El trabajo de Rosanvallon tiene la gran virtud de dejar abiertos importantes considerandos para replantear una renovación democrática, tras comprender la democracia desde tres dimensiones: gobierno electoral-representativo, contrademocracia y trabajo reflexivo y deliberativo de lo político. Sin embargo, la reivindicación del pueblo o de los ciudadanos seguirá difusa mientras estas tres esferas no se analicen de manera integral. Esa es la debilidad de la propuesta de Rosanvallon que quizá, apenas lo planteamos como hipótesis, podría ser reforzada con una reflexión sobre 
tal concepción no es adecuada para una crítica de los límites de la actual democracia existente en las sociedades del capitalismo tardío y demuestra que, por una parte, es preferible una multiplicidad de públicos a una única esfera pública, tanto en sociedades estratificadas como en sociedades igualitarias y, por otro lado, que una concepción sostenible de la esfera pública debe propiciar la inclusión, no la exclusión de los intereses y asuntos que la ideología burguesa machista rotula como privados y trata como inadmisibles; por último, que una concepción defendible de esfera pública debe permitir la existencia tanto de públicos fuertes como de públicos débiles y debe contribuir a la teorización de las relaciones entre ellos (Fraser, 1997). En términos similares, Bohman (1996) hace una crítica a las teorías rawlsianas y habermasianas de la esfera pública y, en respuesta a los dilemas de la diferencia, presenta su modelo dialógico, que pretende ser más pluralista de lo que el discurso habermasiano permite y darle un papel más protagónico a la razón pública crítica del que, en su concepto, le confiere Rawls. Bohman concibe la deliberación como una actividad pública, más que como un procedimiento, como una norma ideal del uso público de la razón comprendida en el contexto de hechos concretos que suelen afectar su realización, como el pluralismo, la inequidad y complejidad sociales. ${ }^{15}$

Respecto a recuperar el rol constitutivo del conflicto en el ámbito político, el trabajo de Chantal Mouffe (1996) es referencia fundamental. ${ }^{16}$ Ella aboga por "el retorno de lo político" y sostiene que las políticas democráticas modernas deben aceptar la división y el conflicto; en este sentido, critica la

el papel de la hegemonía en términos de Gramsci. La organización de la contrademocracia implica pensar procesos contrahegemónicos, los cuales permean las tres esferas de la democracia.

15 "The general structure of these dialogical mechanisms of public deliberation should now be clear: each provides an account of how reasons can secure uptake in deliberation [...]. All the mechanisms discussed depend on symmetry and on other conditions that establish the general framework of equality, non-tyranny, and non-exclusion from the public sphere that is necessary for democratically formed agreements [...] social inequalities block the operation of dialogical mechanisms and thus undermine deliberation" (Bohman, 1996, pp. 65-66). En este sentido, comparte con Fraser la preocupación por los temas distributivos en relación con la posibilidad de empoderamiento político.

16 Sobre el problema del ocultamiento del conflicto social en Rawls, véase también Bensaïd (2003): “[...] en Rawls la ideología no existe o se limita a una cortina de humo que no tiene origen, ni materialidad, ni eficacia propia. La adhesión a las doctrinas comprehensivas no expresa ni relaciones, ni intereses sociales. Procede de una pura elección de conciencia, libre o caprichosa. Es fácil entonces poner creencias y convicciones entre paréntesis en beneficio del consenso" (p. 231). Bensaïd apunta su crítica al velo de la ignorancia como artificio que esconde la mano invisible del mercado: "Para que la mano siga siendo invisible es necesario que el ojo sea ciego" (p. 236). 
pretendida solución racional ofrecida por Rawls al problema de la justicia y señala que en ese marco desaparecen los conflictos, los antagonismos y las relaciones de poder, lo que reduce el campo de lo político a procesos racionales de negociación entre intereses privados dentro de los límites de la moralidad. En conclusión, Mouffe considera que "la sociedad bien ordenada" de Rawls se fundamenta en la eliminación de la idea misma de lo político. Si bien hay que sopesar estas objeciones y considerar la réplica de Rawls (1997) a Habermas, desarollada en "The Idea of Public Reason Revisited", en la que Rawls hace énfasis en que su modelo de democracia deliberativa -el régimen de democracia constitucional apoyado en la razón pública-comprende disensos y supone que el contrato no se cierra, es de recuperar que Fraser, Bohman y Mouffe convergen en una propuesta de democracia radical que pretende trascender la idea rawlsiana. ${ }^{17}$

La siguiente problemática a tratar, la del trato a discapacitados, está relacionada con las luchas por el reconocimiento, en el sentido de que exige aceptar a otro que tiene condiciones físicas o mentales diferentes a las del promedio de la población.

\subsection{La problemática del trato a discapacitados}

Como se mencionó, Kjell Törnblom y Ali Kazemi (2011) identifican esta problemática como de la mayor relevancia hoy:

17 "Un enfoque positivo y militante para la radicalización de la democracia liberal requiere una visión diferente de la política. Una sociedad en la cual han sido erradicados todos los antagonismos está lejos de ser una verdadera democracia, puede ser exactamente lo opuesto. El pluralismo es constitutivo de la democracia moderna, y se opone a cualquier sueño de reconciliación final [...]. La política democrática radical no apunta a la mera inclusión [...] es posible cuestionar los criterios de justicia existentes como acuerdos parciales y provisionales y como producto de una hegemonía dada" (Mouffe, 1996, p. 25).

"[...] debemos encontrar una forma de combinar la lucha por un anti-esencialista multiculturalismo con la lucha por la igualdad social. Únicamente entonces seremos capaces de desarrollar un modelo creíble de democracia radical y una política adecuada para nuestro tiempo" (Fraser, 1996, p. 208).

"[...] radical democracy has two components, one consisting of critical standards and the other consisting of guiding positive ideals. The critical standards are methodological: that democratic ideals (and their philosophical reconstruction) must be constantly tested against the actual social facts of political culture and institutions. The positive ideal is the participation of all citizens in decision making, widely dispersing power in society. Even if deliberation takes place in representative bodies, it still involves the deliberation of all citizens. Such bodies remain deliberative only if citizens vote for and choose their representatives on the basis of participation in public debate and discussion of issues" (Bohman, 1996, pp. 28-29). 
A sad fact of life is that certain individuals and collectives - as well as animals - are excluded from our moral community. Thus, justice is considered irrelevant and not applicable to some people and in some situations and contexts which, in turn, lends legitimacy to morally unacceptable treatment and victimization of humans and other animals (p. 2).

En esta línea, son significativos los aportes de Nussbaum (2007). Ella comparte, en términos generales, el modelo de justicia de Rawls, pero llama la atención sobre el hecho de que no trata con suficiencia tres problemas: el trato a las personas con discapacidad, la justicia más allá del Estado-Nación y la relación con los animales no humanos: "Estoy convencida de que nos encontramos ante tres problemas graves de justicia que no han recibido todavía respuesta. Y pienso defender que la teoría contractualista clásica, incluso en su mejor versión, no puede darnos esa respuesta" (p. 23). En consecuencia, propone tratar tales problemas más allá del contrato social y con un análisis transversal: el de las asimetrías de poder y capacidades. Para ello, expone el enfoque de las capacidades, desarrollado como una variante del enfoque de derechos humanos. ${ }^{18}$

De nuevo, el hecho de que las teorías del contrato social ${ }^{19}$ confundan la cuestión de quién diseña los principios de justicia con la de para quién se diseñan estos principios, significa que no pueden incluir a personas con graves deficiencias físicas o mentales y a ningún animal en el grupo de sujetos para quienes se diseña la teoría, en la medida en que aquellos no toman parte en la elaboración de los contratos (Nussbaum, 2007). En este sentido, el trato a las personas en tales condiciones y a los animales resulta

18 Consideramos que involucrar los asuntos sobre justicia ecológica y del trato a animales no humanos es un reto ineludible para la teoría crítica. Esto exige una ruptura con el enfoque antropocentrista del Derecho; en los términos acá expuestos, una resignificación de los quiénes de la justicia. El desarrollo de esta idea, no obstante, desborda los alcances del presente documento. Véase Nova (2015).

19 Para Nussbaum (2007), la teoría de Rawls se aparta de las concepciones clásicas del contrato social en dos aspectos cruciales: el primero, no atribuye derecho natural a los seres humanos en el estado de naturaleza dentro de su marco de 'justicia procedimental pura'; el segundo, la incorporación de elementos morales en el procedimiento contractual. Esto implica una doble dependencia, dice ella, respecto a la doctrina del contrato social y a las ideas centrales de la filosofia moral kantiana, lo cual es, a la vez, fuente de iluminación y de una profunda tensión dentro de la teoría de Rawls. Sin embargo, la teoría de Rawls también queda en deuda en cuanto a los tres problemas de la justicia que ella señala (pp. 42-44). 
una cuestión de caridad, más que de justicia, lo que para Nussbaum constituye un manejo insuficiente.

Para retomar la distinción que hace Rawls entre la situación de elección originaria y los principios de justicia como dos partes de la teoría que pueden ser aceptadas o no, de manera independiente, declara Nussbaum (2007) su rechazo a la primera así como su simpatía por los segundos. Dice que los principios en sí son buenos, que las ideas de equidad y reciprocidad sobre los que se erigen son ideas éticas muy atractivas, incluso para ser extendidas a aquellas problemáticas no atendidas por la teoría misma. Se propone "llegar a principios próximos a los de Rawls por una ruta distinta [...] partiendo de una concepción debidamente ampliada de la reciprocidad y la dignidad" (p. 44).

En adhesión al modelo liberal de Rawls, Nussbaum usa el enfoque de las capacidades como base filosófica para una teoría de los derechos básicos de los seres humanos que deben ser respetados y aplicados por los Gobiernos de todos los países, como requisito mínimo del respeto por la dignidad humana:

La idea intuitiva básica de mi versión del enfoque de las capacidades es que debemos partir de una concepción de la dignidad del ser humano, y de una vida acorde con esa dignidad; una vida que incluye un funcionamiento auténticamente humano, en el sentido descrito por Marx en los Manuscritos de Economía y Filosofía de 1844 [.... Partiendo de esta idea básica, pretendo justificar una lista de diez capacidades como requisitos básicos para una vida digna: vida; salud física; integridad física; sentidos, imaginación y sentimientos; emociones; razón práctica; afiliación; otras especies; juego; control sobre el propio entorno (político y material) (Nussbaum, 2007, p. 20).

Tales capacidades aplican a todo ser vivo, humano y no humano. ${ }^{20}$

El problema de la justicia más allá del Estado Nación amerita su propio apartado.

20 Sobre la lista de capacidades aplicada a los animales, véase Nussbaum (2007, pp. 385-394). 


\subsection{La problemática de la justicia transnacional}

Young (1998) reseña como insuficientes los aportes teóricos de esta problemática en momentos en los que las sociedades son confrontadas con problemas prácticos y morales como la interdependencia entre países pobres y países ricos, la amenaza de una catástrofe ecológica global y los masivos flujos de refugiados y emigrantes, entre otros problemas propios de la globalización:

En Political Theory and International Relations (1979), Charles Beitz arguye que los principios de justicia establecidos por Rawls pueden servir de base para evaluar y criticar la desigualdad distributiva entre las sociedades desarrolladas del Norte y las subdesarrolladas del Sur. Años después, Thomas Pogge ha elaborado una cuidadosa y persuasiva ampliación a escala planetaria de la aproximación rawlsiana a los problemas de la justicia. Pese a ello, la teoría política de la desigualdad socioeconómica transnacional sigue estando subdesarrollada. La teorización social y política de la desigualdad social y económica entre países permanece subdesarrollada (pp. 699-700).

Nussbaum (2007) sostiene que Kant y Rawls plantean la cuestión de la justicia transnacional de manera marginal, mediante principios posteriores para regular las relaciones entre Estados, de modo que en este enfoque aquellos son considerados también libres, iguales e independientes. Así, los problemas y las necesidades de los países pobres aparecen como cuestiones de caridad y no de justicia básica. ${ }^{21}$ En cuanto a la teoría de Hugo

21 "La cuestión de la justicia entre naciones era en cierto modo imposible de esquivar en el mundo de las doctrinas clásicas del contrato social. Los principales teóricos estaban demasiado familiarizados con las guerras entre Estados y con los fenómenos del comercio y la expansión colonial. Pero entonces parecía posible adoptar un enfoque débil sobre las relaciones internacionales, centrado en las cuestiones relativas a la guerra y la paz, y negarse a entrar en cuestiones de redistribución económica o de protección de los derechos humanos básicos [...]. Este enfoque débil caracteriza hoy las prácticas de los países ricos y nuestros sistemas de derecho internacional, y cada vez se demuestra más inadecuado para el mundo en el que vivimos. Existen grandes diferencias entre países ricos y pobres en todas las áreas que definen las oportunidades vitales básicas: mortalidad, salud, educación, etc. Incluso si ponemos entre paréntesis las cuestiones de justicia retrospectiva generadas por el legado del colonialismo, una reflexión crítica sobre las operaciones del sistema económico global, que es controlado por un reducido número de países, pero tiene un impacto decisivo sobre todos los demás, plantea cuestiones de justicia urgentes de cara al futuro" (Nussbaum, 2007, p. 40). 
Grocio sobre las relaciones internaciones, ${ }^{22}$ Nussbaum (2007) ilustra que posturas que apuntan a considerar una distribución de excedentes entre países, propuestas radicales sobre la propiedad y la necesidad, no podrían sostenerse sobre las premisas del contrato social: "[...] la lógica misma de un contrato orientado al beneficio mutuo sugiere la exclusión de aquellos agentes cuya contribución al bienestar social general será con toda probabilidad muy inferior a la de los demás" (p. 39). Presenta diez principios para la estructura global: sobredeterminación de la responsabilidad; respeto de la soberanía nacional dentro de los límites de la promoción de las capacidades humanas; responsabilidad de Naciones prósperas de compartir su PIB con Naciones más pobres; responsabilidad de grandes empresas multinacionales en la promoción de capacidades humanas en las regiones que operan; diseño justo de las estructuras del orden económico mundial en relación con los países pobres y en vía de desarrollo; una esfera pública tenue, descentralizada, pero contundente; atención por parte de todas las instituciones y la mayoría de los individuos a los problemas de los desfavorecidos en cada Nación y en cada región; actuación de la comunidad internacional enfocada en la atención a los enfermos, las personas mayores, los niños y discapacitados; reconocimiento de la familia como ámbito de gran valor, no privado; promoción de la educación como clave para dar oportunidades a las personas actualmente desfavorecidas.

Benhabib (2006) ubica el trabajo de Rawls en una corriente conservadora entre los estudios de las relaciones internacionales y cuestiona, en primera medida, la perspectiva que adopta sobre la justicia internacional como un caso especial de la justicia representada por las instituciones del Estado nacional, lo que limita así la posibilidad de exigir derechos fuera de este marco jurídico y, en segundo término, porque deja sin sustento conceptual una reflexión sobre problemas críticos como las migraciones. En consecuencia, aboga por un federalismo cosmopolita.

Fraser (2008) plantea la necesidad de "reenmarcar la justicia en un mundo en globalización" (pp. 31-64). Analiza la legitimidad y la eficacia de la opinión pública en un mundo poswestfaliano a partir del reconocimiento

22 Cabe anotar que, en general, los trabajos de las feministas han nutrido el enfoque reflectivista del estudio de las relaciones internacionales y reivindican la sociedad internacional como perspectiva de análisis normativo. De esta manera, crean puntos de encuentro con la perspectiva racionalista en la que se ubica a Grocio. Véase Sodupe (2003). 
del poder crítico de la teoría de la esfera pública y de las limitaciones de los debates actuales. ${ }^{23}$ Su objetivo es politizar de nuevo la esfera pública frente a la amenaza de que se vea despolitizada, reformular la teoría crítica de la esfera pública de modo que pudiera ilustrar las posibilidades emancipadoras de la constelación presente.

Fraser quiere destacar que tanto el modelo deliberativo de democracia de Habermas como los planteamientos de sus críticos, por igual en las corrientes de la legitimidad y la eficacia, ${ }^{24}$ han dado por supuesto el enmarque westfaliano del espacio político. Así, pone de presente la necesidad de pensar la esfera pública en un marco transnacional ${ }^{25}$ y reformular los supuestos centrales de la teoría referentes a la legitimidad y a la eficacia de la opinión pública.

Por otra parte, encontramos las reflexiones de Wellmer en Finales de partida (1996), en donde sostiene que la elección de un punto de referencia específico, sea de Estados nacionales, Estados constitucionales o la Unión Europea, resulta irrelevante para la construcción de orientaciones

23 "En general, pues, el debate sobre la esfera pública en la teoría crítica contiene un notable punto débil [...] prácticamente todos los participantes en el debate, yo misma incluida, correlacionaban las esferas públicas con los Estados territoriales. A pesar de otros importantes desacuerdos, todos asumíamos el enmarque westfaliano del espacio político, justo en un momento en el que los desarrollos históricos de la época parecían que ya estaban cuestionando este mismo marco" (Fraser, 2008, p. 161).

24 Habermas se propuso evaluar en términos de legitimidad y de eficacia existente en el Estado moderno westfaliano. Algunos de sus lectores consideraron que su crítica no fue suficientemente radical. Una corriente de los mismos se concentró en el tema de la legitimidad y destacó la presencia de obstáculos sistémicos que impiden que muchas personas tengan la capacidad de participar en condiciones de igualdad en el debate público. Una segunda corriente radicaliza el cuestionamiento habermasiano de la eficacia de la opinión pública y considera los obstáculos sistémicos que despojan de músculo político a la opinión pública: "[...] al destacar los respectivos roles de poder económico privado y los intereses burocráticos consolidados, su crítica sirvió para dudar aún más de la eficacia de la opinión pública como fuerza política en las sociedades capitalistas" (Fraser, 2008, p. 156).

25 "En general, pues, las esferas públicas son cada vez más transnacionales o posnacionales con respecto a cada uno de los elementos constitutivos de la opinión pública. El 'quién' de la comunicación, conceptualizado antes como población nacional westfaliana, es a menudo ahora una colección de interlocutores dispersos, que no constituyen un demos. El 'qué' de la comunicación, que se teorizaba antes como el interés nacional-westfaliano enraizado en una economía nacional-westfaliana, se extiende ahora por vastas regiones del planeta, en una comunidad transnacional de riesgo, pero que, sin embargo, no se refleja en amplias solidaridades e identidades que lo acompañen. El 'dónde' de la comunicación, que la teoría antes entendía como el territorio nacional-westfaliano, es ahora un ciberespacio desterritorializado. El 'cómo' de la comunicación, que la teoría antes identificaba con los medios de comunicación impresos, ahora abarca un extenso entramado translingüístico de culturas disjuntas que se solapan. Por último, el 'a quién' o destinatario de la comunicación, es ahora una mezcla amorfa de poderes públicos y privados que ni son fácilmente identificables ni son susceptibles de tener que rendir cuentas de nada" (Fraser, 2008, pp. 173-174). 
normativas. Los problemas de justicia hoy deben inscribirse en una "sociedad mundial" construida liberal y democráticamente. Wellmer propone la perspectiva de una sociedad cosmopolita como el horizonte normativo de las tradiciones democráticas y liberales de la Modernidad, una sociedad cosmopolita que elimine la diferencia entre los derechos del hombre y los derechos del ciudadano o al menos los articule apropiadamente. Su tesis es que la idea kantiana de un estado jurídico de tipo cosmopolita es una noción inscrita inevitablemente en el discurso democrático moderno (Wellmer, 1996).

Anticipado a posibles objeciones por las implicaciones universalistas de su propuesta, sostiene Wellmer (1996) que universalismo y contextualismo no son conceptualmente opuestos y que, además, una "política de las diferencias" no es viable sin el trasfondo de principios morales y jurídicos de corte universalista: "Por tanto, la perspectiva de una sociedad cosmopolita representa la condición incluso de un pacífico pluralismo cultural en el mundo moderno" (p. 100). En este orden, dice Wellmer, es ineludible dar primacía a los derechos liberales sobre los comunitaristas: la defensa de los principios democráticos y liberales constituye la única protección posible contra la destrucción violenta de las tradiciones e identidades culturales. Sin embargo, señala, es innegable que la superación de lo particular en lo general tiene implicaciones de tipo moral:

[...] todo parece indicar que con el tránsito a un Estado jurídico de tipo cosmopolita también se reproducirá a escala mundial la "tragedia de lo ético", ya que la relativización de las tradiciones culturales particulares significa a la vez su transformación y su parcial depotenciación (p. 100).

Este es el implacable e inevitable precio de la Modernidad, concluye.

Sen (2010) sostiene que existen dos principales razones para exigir que el encuentro del razonamiento público con la justicia vaya más allá de las fronteras del Estado o de una región, una relacionada con la interdependencia de los intereses y la otra con la necesidad de eludir la trampa del parroquialismo y, en estos términos, defiende una participación activa para aspirar a una justicia global. Concluye que la distribución de beneficios de 
las relaciones globales no depende en exclusiva de las políticas domésticas, sino que requiere una variedad de arreglos sociales internacionales. ${ }^{26}$

\section{Los alcances y las limitaciones del concepto de género como referente de justicia social}

Una vez enunciadas las cuatro principales problemáticas de la justicia que han cobrado lugar en los debates contemporáneos con, contra y más allá de Rawls, es pertinente ubicarlas dentro la situación social, económica y política contemporánea, caracterizada por Fraser (1997) como la condición postsocialista:

Esta es pues la condición "postsocialista", la ausencia de un proyecto emancipatorio amplio y creible, a pesar de la proliferación de frentes de lucha; una escisión generalizada entre las políticas culturales de reconocimiento y las políticas sociales de redistribución, y el alejamiento de las pretensiones de igualdad frente a una agresiva mercantilización y un agudo crecimiento de las desigualdades materiales (p. 7).

En consecuencia, una concepción de la justicia requiere una aproximación crítica "bivalente", integrar lo social y lo cultural, lo económico y lo discursivo (Fraser, 1997).

Tal dualismo perspectivista, en palabras de Fraser, parte del supuesto de que: "Sólo un marco que integre las dos perspectivas, analíticamente distintas, de la redistribución y el reconocimiento puede recoger la imbricación de la desigualdad de clase y la jerarquía de status de la sociedad contemporánea (Fraser y Honneth, 2006, p. 14). ${ }^{27}$ Por lo tanto, en este documento se propone estructurar las cuatro problemáticas enunciadas en dos irreductibles dimensiones de la justicia: redistribución y reconocimiento,

26 Véase Sen (2010, cap. 18).

27 Si bien el presente análisis se inscribe en la corriente de pensamiento de la teoría crítica, con epicentro en la Escuela de Frankfurt y sus diálogos posrawlsianos sobre justicia social con las feministas estadounidenses, es de referenciar y resaltar las cercanías de estos planteamientos con las luchas latinoamericanas, como lo expone Boaventura de Sousa Santos (2003) en su propuesta de reinventar un paradigma subalterno de reconocimiento y redistribución en el marco de una cultura política transnacional emergente. 
incluidos en esta última los asuntos del trato a personas con diversas capacidades y asuntos transnacionales, con base en una reconceptualización de los quiénes de la justicia. La invitación consiste en cuestionar el presupuesto de personas libres e iguales y reconocer las diferencias; es más, asumir que no existen colectividades puras, pues en la práctica se constituyen grupos que se ven afectados por entrecruces de injusticias por falta de reconocimiento y mala distribución, como puede ser el caso de una mujer afrodescendiente, cabeza de familia, pobre y desempleada. Como lo expone Fraser (1997), las propias injusticias de género y raza se afianzan tanto en el marco de la división del trabajo como en la estructura cultural valorativa, en otras palabras, son colectividades bivalentes paradigmáticas.

El recorrido teórico por las cuatro grandes problemáticas de la justicia permite ilustrar los alcances y las limitaciones del concepto de género en el amplio espectro de formas de opresión en la sociedad contemporánea. La categoría de género es una dimensión fundamental de la justicia social; no obstante, es insuficiente. Las cuestiones de género, asumidas como una categoría dentro de la lucha por el reconocimiento, por una parte, deben complementarse en su análisis con los asuntos de justicia distributiva y, por otro lado, el género debe tomarse apenas como una forma de diferencia, la cual ha de venir acompañada de consideraciones como raza, religión, condiciones físicas y mentales. Esta reformulación teórica es una invitación a repensar los quiénes de la justicia.

\subsection{Repensar los quiénes de la justicia: condiciones objetiva e intersubjetiva de paridad participativa}

Para compatibilizar las dos dimensiones de la justicia, Fraser (2008) propone comprender el reconocimiento no como un asunto de autorrealización en el sentido que atribuye a Honneth y Taylor, sino como una cuestión de justicia, esto es, como un asunto de estatus social. El reconocimiento, sostiene, es el remedio de una injusticia social y no la satisfacción de una necesidad humana genérica. Lo injusto consiste en negarle a alguien el carácter de interlocutor válido en la interacción social por cuenta de unos marcos valorativos institucionalizados, de cuya elaboración aquel no formó parte activa. En otras palabras, lo injusto es que se construya una clase de 
personas socialmente devaluadas; lo injusto es que no puedan participar a plenitud de la interacción social.

Fraser (Fraser y Honneth, 2006) resalta que los patrones institucionalizados de valor cultural pueden tener efectos diferenciados sobre el prestigio de los diversos actores sociales. Pueden favorecer una igualdad de estatus o reconocimiento recíproco o, por el contrario, fomentar un reconocimiento erróneo y una subordinación de estatus. En estos términos, concluye Fraser que el propósito de la justicia es desinstitucionalizar los patrones de valor cultural que impiden la paridad de participación y reemplazarlos por patrones que la favorezcan. ${ }^{28}$

El núcleo normativo de Fraser (Fraser y Honneth, 2006) es la paridad de participación, la posibilidad de intervenir en las decisiones sociales, sea que lo hagan o se abstengan de hacerlo. Es la condición para construir acuerdos sociales, lo que Rawls llamaría "consenso entrecruzado". La condición objetiva de la paridad participativa es la distribución equitativa de recursos materiales, que garantice la independencia y la voz de todos los participantes. La condición intersubjetiva es la igualdad de estima social. La objetiva rechaza cualquier expresión de explotación, dependencia o desigualdad económica. La intersubjetiva exige patrones institucionalizados que expresen igual respeto para todos y las mismas oportunidades para obtener la estima social. Una y otra condición, sostiene Fraser (Fraser y Honneth, 2006), son indispensables para alcanzar la paridad participativa.

El análisis historiográfico de la esfera pública que elabora Fraser (1997) la lleva a cuestionar, entre otros, el postulado de una concepción burguesa de la esfera pública liberal según el cual "los interlocutores pueden poner entre paréntesis sus diferencias y deliberar 'como si' fueran socialmente iguales" (p. 107). Así, busca reivindicar el papel de la reflexión sobre la distribución, que ha de acompañar la de la lucha por el reconocimiento: "Una concepción adecuada de la esfera pública exige, no solo poner en suspenso la desigualdad social, sino eliminarla" (p. 132).

28 "Las luchas por el reconocimiento tienen lugar en un mundo de exageradas desigualdades materiales - en cuanto a ingresos y propiedad, acceso al trabajo remunerado, educación, salud y recreación, pero también, y de modo más descarnado, en cuanto al insumo de calorías y a la exposición a entornos tóxicos y, por lo tanto, en cuanto a las expectativas de vida y a las tasas de morbilidad y mortalidad" (Fraser, 1997, pp. 17-18). 
Más allá del culturalismo y del economicismo, la significativa correlación que se presenta entre pobreza y situación social en términos de raza, género, etnicidad y cultura, por ejemplo, denotan que es falsa la supuesta dicotomía entre reconocimiento y redistribución. Fraser (Fraser y Honneth, 2006) lo ilustra específicamente con la categoría de género, cuando las discriminaciones responden tanto a valores institucionalizados como a exclusiones de tipo económico. ${ }^{29}$

Existen injusticias socioeconómicas que se traslapan con patrones sociales de representación y que, a su vez las profundizan, como es el caso de la falta de reconocimiento por género o raza. En este sentido, la falta de reconocimiento derivada de la economía política, esto es, de injustas distribuciones de beneficios y cargas, debe ser corregida. Categorías como género o raza, por ejemplo, concebidas como criterio de diferenciación político-económica, fomentan formas de explotación, marginación y pobreza, es decir, constituyen colectividades subordinadas. Con el componente económico, por supuesto, está el de diferenciación cultural valorativa que, en todo caso, debe modificarse. En cuanto al género, esto significa desmantelar el androcentrismo. Lo que acá se destaca es que el cambio en el patrón simbólico se favorece al corregir las desventajas económicas, pues de este modo se propicia la igual participación en la construcción de representaciones culturales. En otras palabras, las transformaciones culturales valorativas para defender la especificidad de colectividades menospreciadas se ven respaldadas por la igualdad en la participación para la construcción social de normas y significaciones.

Puesto que no existen colectividades puras, estos principios normativos atenderían ciertas injusticias de reconocimiento que surgen en las intersecciones de clase, raza, género o preferencia sexual. Es la desigualdad producida por la ruptura entre trabajo formal y actividades del cuidado, que convierte a las mujeres en copartícipes de una desventaja económica y de una falta de aprecio social.

29 Sin duda, las desventajas económicas obstaculizan la igual participación en la construcción de patrones sociales de interpretación, representación, comunicación y evaluación, tanto en las esferas públicas como en la vida privada. No obstante, al mismo tiempo se reconoce, como bien lo precisa Fraser (1997), que los cambios sustanciales de modificación en los patrones de valoración cultural que promueven déficit de reconocimiento requieren soluciones adicionales. 


\subsection{Repensar los quiénes de la justicia: género y más}

La pregunta por los quiénes de la justicia es fundamental para articular redistribución y reconocimiento. La invitación a reconceptualizarlos (quiénes) apunta a desmontar el supuesto de ciudadanos libres e iguales que heredan las teorías de la justicia del contractualismo. Las personas son diversas, distintas, con diferentes doctrinas religiosas, filosóficas y morales, así como por variadas condiciones socioeconómicas y desiguales dotaciones naturales. Desde esta perspectiva, se procura redescubrir la heterogeneidad que se pierde en la simple distinción de los grupos de ciudadanos más y menos aventajados, en los términos rawlsianos.

Sobre los quiénes de la justicia son fundamentales los aportes de Fraser (2008) y Nussbaum (2007), reseñados en el capítulo anterior, con el fin de trascender las concepciones hegemónicas del quién. Esta cuestión permite considerar las importantes problemáticas sobre la justicia social del trato a personas con deficiencias físicas o mentales y sobre la justicia transnacional.

Recuérdese que Nussbaum (2007) desarrolla una crítica al criterio fundamental del beneficio mutuo de la teoría clásica del contrato social, la cual propicia que al menos tres problemas de la justicia no queden resueltos: el trato a las personas discapacitadas, el alcance de la justicia más allá del Estado-Nación y la relación con los animales no humanos. En consecuencia, propone el enfoque de las capacidades, entendido como una variante del enfoque de derechos humanos, como la mejor forma de abordar tales problemas y señala que cada uno de ellos requiere un abordaje independiente, más allá del contrato social y con un análisis transversal: el de las asimetrías de poder y capacidades.

El trato a los discapacitados exige reconocer al otro que tiene condiciones distintas a las del promedio y la relación con los animales es un ejercicio también de reconocimiento, en la medida en que se aparte de la perspectiva antropocéntrica predominante en las teorías de la justicia.

Considerar la igualdad de capacidades antes que de recursos permite cubrir con respeto a las personas con variadas condiciones físicas o mentales, incluidos los discapacitados y los niños. En relación con una máxima dignidad, se comprende la diversidad de satisfactores que pueden definirse culturalmente y de acuerdo con las condiciones físicas y mentales de cada persona. 
Este asunto es la preocupación central de Young (2000) cuando, influenciada por Walzer (1983), expresa que es importante tener presente que la igualdad absoluta es, como dijera Aristóteles, una absoluta injusticia, en la medida en que implica violar un fundamento de la equidad de tratar de manera distinta a quienes acreditan ciertas diferencias moralmente relevantes.

Las personas en situación de dependencia requieren asistencia especial, bienes, servicios, actividades y relaciones particulares que abarquen todo el espectro de las capacidades humanas básicas: todos pueden ser capaces de realizar las funciones básicas de la lista con una asistencia adecuada. En efecto, Nussbaum (2007) insiste en la importancia de mantener una única lista de capacidades como fundamento de igual respeto hacia todos los seres humanos:

Si adoptáramos una lista de capacidades para los "normales" y otra para los "niños con síndrome de Down", como si fueran una especie distinta, esta lamentable tendencia se vería reforzada: la implicación sería que los "normales" son individuos (tal como ellos saben perfectamente y nadie se lo discute), mientras que los niños con síndrome de Down son un tipo sin ninguna individualidad ni diversidad significativa, definido enteramente por sus características típicas (p. 195).

Otra dimensión de la reformulación de los quiénes de la justicia permite abordar los problemas de la justicia transnacional. Dadas las formas de política "interméstica", el carácter transterritorial de los problemas como el calentamiento global, entre otros, el postulado de una soberanía estatal indivisa y exclusiva no es sostenible hoy. Fraser (2008) aborda esta cuestión al proponer redibujar los límites de la justicia a una escala más amplia. Esta tarea supone discutir el enmarque westfaliano de la justicia, que concibe las comunidades políticas como unidades geográficamente delimitadas, asociadas con un Estado propio. En este marco conceptual, el espacio político internacional se contempla como un estado de naturaleza que debería ser sustituido por el debate democrático y la constitución de un marco institucional de toma de decisiones transnacionales. En suma, esboza argumentos a favor de una "metademocracia" transnacional, una justicia democrática poswestfaliana. 
Para Fraser (2008), estos fenómenos exigen la redefinición del quién de la justicia: "El problema surge de los enmarques conflictivos del quién: ¿ciudadanías territorializadas, humanidad global o comunidades de riesgo transnacional? [...] la cuestión es quién cuenta como auténtico sujeto de la justicia" (p. 21).

Alentada por los nutridos debates suscitados por El Derecho de gentes de Rawls (2001), reseñados en el capítulo anterior, Fraser propone una teoría crítica del enmarque para clarificar el quién de la justicia. Frente al problema de las injusticias transfronterizas, sugiere una política de representación transnacional. Ante la metainjusticia del desenmarque, afirma, aparece una nueva dimensión de la justicia, más allá de la distribución y del reconocimiento, a la que denomina representación.

Mas del problema del desenmarque no se sigue necesariamente la incorporación de una nueva dimensión de la justicia. Si la cuestión es de escalas, en cualquiera de ellas la representación podría considerarse un mecanismo válido para ejercer la paridad participativa, pero es solo un medio para dar tránsito a las reivindicaciones de reconocimiento y redistribución. La representación no constituye un concepto del mismo rango conceptual dentro de la consideración de las injusticias contemporáneas, caracterizadas por falta de reconocimiento y mala distribución. En cualquier esfera de la dimensión política, como ella las describe, tanto en la metapolítica como en la política ordinaria, el referente normativo ha de ser una democracia radical. Paradójicamente, Fraser (2008) justifica lo político desde una dimensión instrumental y lo describe como el espacio de las reglas de decisión y los procedimientos para tratar los conflictos económicos y sociales: "[...] centrada en cuestiones de pertenencia y procedimiento, la dimensión política de la justicia se interesa sobre todo por la representación" (p. 42). ${ }^{30}$

30 No se pretende polemizar sobre la funcionalidad de reglas de decisión; lo que se cuestiona es que la representación se configure como dimensión de la justicia en el mismo grado del reconocimiento y de la redistribución. Por lo anterior, los planteamientos de Fraser (2008) cargan cierta inconsistencia en relación con una idea de justicia como paridad participativa y la injusticia particular de la representación como no institucionalización de la paridad en la participación. Al ser lo político, como ella lo describe, el escenario en donde se desarrollan las luchas por la justicia social, repensar los quiénes de la justicia no implica reformular el qué de la justicia. La representación podría considerarse una respuesta, en todo caso parcial, a la pregunta del cómo, sugerida por una, eso sí acertada, revaluación del quién, pero no es claro que signifique un replanteamiento del qué de la justicia. Para ilustrarlo con sus representaciones, cambiar la escala del mapa no equivale a modificar la balanza. 
En todo caso, dentro de una concepción política de la justicia han de considerarse las injusticias de falta de reconocimiento y mala distribución más allá de las fronteras nacionales. En este orden, al desenmarcar los quiénes del territorio nacional, pueden incorporarse las reivindicaciones de públicos que no coinciden con las ciudadanías territoriales, inmersos en economías que no son estrictamente nacionales. Son ineludibles los problemas de la justicia global asociados con las profundas y progresivas desigualdades socioeconómicas planetarias, la localización de los daños ecológicos y la explotación y el consumo de los recursos naturales.

\section{Conclusiones}

Mediante una revisión de los debates de Filosofía Política contemporánea sobre justicia social, se mostró que la teoría crítica hoy tiene el gran reto de abordar en un mismo marco interpretativo las distintas formas de injusticia. En consecuencia, se propuso reestructurar las cuatro grandes problemáticas identificadas en dos irreductibles dimensiones de la justicia: redistribución y reconocimiento. Con base en una reconceptualización de los quiénes de la justicia, la segunda dimensión, el reconocimiento, además de los asuntos de género comprende el trato a personas con diversas capacidades físicas y mentales y los conflictos transnacionales. Este marco interpretativo permite ilustrar los alcances y las limitaciones de la categoría de género como instrumento de análisis de las injusticias, violencias, opresiones y la discriminación presentes en la sociedad actual.

Una concepción política de la justicia hoy ha de comprender la defensa tanto del reconocimiento como de la redistribución como dos categorías cofundamentales e irreductibles entre ellas. Articular estas categorías, que comprenden las graves injusticias identificadas por la Filosofía Política contemporánea, exige repensar los quiénes de la justicia. La invitación a reconceptualizarlos (quiénes) apunta a desmontar el supuesto de ciudadanos libres e iguales que heredan del contractualismo las teorías de la justicia. Las personas son diversas, distintas, conformadas por diferentes doctrinas religiosas, filosóficas y morales, así como por variadas condiciones socioeconómicas y desiguales dotaciones naturales. Reconocer las diferencias implica asumir que no existen colectividades puras, esto es, que en la práctica 
se constituyen grupos que se ven afectados por entrecruces de injusticias de falta de reconocimiento y mala distribución, como puede ser el caso de una mujer afrodescendiente, cabeza de familia, pobre y desempleada.

La categoría de género es una dimensión fundamental de la justicia social; no obstante, es insuficiente. Las cuestiones de género, entendidas como una categoría dentro de la lucha por el reconocimiento, por una parte, deben complementarse en su análisis con los asuntos de justicia distributiva y, por otro lado, el género debe entenderse apenas como una forma de diferencia, que ha de venir acompañada de consideraciones como nacionalidad, raza, religión, condiciones físicas y mentales.

\section{Referencias}

Benhabib, S. (2006a). El ser y el otro en la ética contemporánea. Barcelona: Gedisa.

Benhabib, S. (2006b). Las reivindicaciones de la cultura, igualdad y diversidad en la era global. Buenos Aires: Katz.

Bensaïd, D. (2003). Marx intempestivo. Grandezas y miserias de una aventura crítica. Buenos Aires: Herramienta.

Bohman, J. (1996). Public Deliberation. Cambridge: MIT Press.

Cohen, G. (2001), Si eres igualitarista, ¿cómo es que eres tan rico? Barcelona: Paidós. D'Agostini, F. (2000). Analíticos y continentales. Guía de la filosofía de los últimos 30 años. Madrid: Cátedra.

De Sousa Santos, B. (2003). Nuestra América: la formulación de un nuevo paradigma subalterno de reconocimiento y redistribución. En Autor (ed.), La caída del Angelus Novus: ensayos para una nueva teoría social y una nueva práctica política (pp. 81-122). Bogotá: Universidad Nacional de Colombia.

Fraser, N. (1997). Iustitia Interrupta. Bogotá: Siglo del hombre.

Fraser, N. (2008). Escalas de justicia. Barcelona: Herder.

Fraser, N. y Honneth, A. (2006). ¿Redistribución o reconocimiento? Madrid: Morata. Habermas, J. y Rawls, J. (1998). Debate sobre el liberalismo politico. Barcelona: Paidós. Honneth, A. (2009). Patologías de la razón. Historia y actualidad de la teoría crítica. Buenos Aires: Katz.

MacIntyre, A. (1981). After Virtue. Londres: Duckworth.

Mejía, O. (2010). Modelos alternativos de democracia deliberativa. Co-herencia, 7(12), 43-79. 
Mouffe, C. (1996). Radical Democracy or Liberal Democracy. En D. Trend (ed.), Radical Democracy (pp. 19-26). Nueva York: Routledge.

Múnera, L. (2001). La tragedia de lo público. Trans, 1(1), 224-243.

Nova, M. (2015). Hacia una utopía realista: redistribución y reconocimiento. Una concepción política de justicia como fundamento de una aproximación a un índice de justicia social. (Tesis doctoral inédita). Universidad Nacional de Colombia Bogotá.

Nozick, R. (1974). Anarchy, State and Utopia. Nueva York: Basic Books.

Nussbaum, M. (2007). Las fronteras de la justicia. Barcelona: Paidós.

Rawls, J. (1997). The Idea of Public Reason Revisited. The University of Chicago Law Review, 64(3), pp. 765-807.

Rawls, J. (2001). El Derecho de gentes. Barcelona: Paidós.

Rawls, J. (2002). La justicia como equidad, una reformulación. Barcelona: Paidós.

Rawls, J. (2006). Liberalismo político. México D. F.: Fondo de Cultura Económica.

Rawls, J. (2011). Teoría de la justicia. México D. F.: Fondo de Cultura Económica.

Rosanvallon, P. (2006). La contrademocracia. La politica en la era de la desconfianza. Buenos Aires: Manantial.

Sandel, M. (2000). El liberalismo y los límites de la justicia. Barcelona: Gedisa.

Sen, A. (1988). ¿Igualdad de que? En S. Mcmurrin (ed.), Libertad, igualdad y derecho, pp. 133-156. Barcelona: Ariel.

Sen, A. (2010). La idea de la justicia. Bogotá: Taurus.

Sodupe, K. (2003). La teoría de las relaciones internacionales a comienzos del siglo XXI. Bilbao: Universidad del País Vasco.

Törnblom, K. y Kazemi, A. (2011). Social Justice Research: Mission, Some Prospects, and Challenges. Social Justice Research, 24(1), 1-5.

Van Parijs, P. (1996). Libertad real para todos. Barcelona: Paidós.

Van Parijs, P. (2008). Ingreso básico: una simple y poderosa idea para el siglo XXI. En E. Wright (ed.), Repensando la distribución. Bogotá: Siglo del Hombre Editores, Universidad de los Andes.

Van Parijs, P. y Van der Veen, R. (1988). Una vía capitalista al comunismo. Zona Abierta, pp. 46-47, pp. 19-46.

Walzer, M. (1983). Spheres of Justice. Nueva York: Basic Books.

Wellmer, A. (1996). Finales de partida: la modernidad irreconciliable. Madrid: Cátedra. Young, I. (1998). Political Theory: An Overview. En R. G. Klingemann (ed.), Political Science, pp. 479-502. Oxford: Oxford University Press.

Young, I. (2000). La justicia y la politica de la diferencia. Valencia: Universidad de Valencia. 